\title{
Spectral Indices: In-Season Dry Mass and Yield Relationship of Flue-Cured Tobacco under Different Planting Dates and Fertiliser Levels
}

\author{
Ezekia Svotwa, ${ }^{1}$ J. Anxious Masuka, ${ }^{2}$ Barbara Maasdorp, ${ }^{3}$ and Amon Murwira ${ }^{3}$ \\ ${ }^{1}$ Department of Crop Science, University of Zimbabwe, Harare, Zimbabwe \\ ${ }^{2}$ Department of Geography and Environmental Studies, University of Zimbabwe, Harare, Zimbabwe \\ ${ }^{3}$ Tobacco Research Board/Kutsaga Research Station, Harare, Zimbabwe \\ Correspondence should be addressed to Ezekia Svotwa; esvotwa2@gmail.com
}

Received 18 July 2013; Accepted 13 August 2013

Academic Editors: O. Ferrarese-Filho and J. Hatfield

Copyright (C) 2013 Ezekia Svotwa et al. This is an open access article distributed under the Creative Commons Attribution License, which permits unrestricted use, distribution, and reproduction in any medium, provided the original work is properly cited.

\begin{abstract}
This experiment investigated the relationship between tobacco canopy spectral characteristics and tobacco biomass. A completely randomized design, with plantings on the 15th of September, October, November, and December, each with 9 variety $\times$ fertiliser management treatments, was used. Starting from 6 weeks after planting, reflectance measurements were taken from one row, using a multispectral radiometer. Individual plants from the other 3 rows were also measured, and the above ground whole plants were harvested and dried for reflectance/dry mass regression analysis. The central row was harvested, cured, and weighed. Both the maximum NDVI and mass at untying declined with later planting and so was the mass-NDVI coefficient of determination. The best fitting curves for the yield-NDVI correlations were quadratic. September reflectance values from the October crop reflectance were statistically similar $(P>0.05)$, while those for the November and the December crops were significantly different $(P<0.05)$ from the former two. Mass at untying and NDVI showed a quadratic relationship in all the three tested varieties. The optimum stage for collecting spectral data for tobacco yield estimation was the 8-12 weeks after planting. The results could be useful in accurate monitoring of crop development patterns for yield forecasting purposes.
\end{abstract}

\section{Background}

Crop yield estimation in many countries is based on conventional techniques of data collection and ground-based field reports [1]. A variety of mathematical models relating to crop yield have also been proposed in recent years for many crops $[2,3]$. In Zimbabwe crop surveys are mostly used in estimating crop yield [4]. The method is costly, time consuming, and is prone to large errors due to incomplete ground observations, leading to poor crop yield assessment and crop area estimations [1].

Remote sensing data has the potential and the capacity to provide spatial information in a global scale of features and phenomena on earth on an almost real-time basis [1]. Use of remote sensing techniques has the potential to provide quantitative and timely information on agricultural crops over large areas, and many different methods have been developed to estimate crop yields [5-7]. In general, the use of remote sensing was aimed at reducing the number of samples of ground surveys, making it less expensive [8]. With the application of remote sensing in agriculture, there is potential not only in identifying crop classes but also in estimating crop yield [1].

Spectral measurements from crops can be used in estimating crop parameters such as leaf area index [9], plant population, and even canopy total nitrogen status during the growth cycle of the crop [10]. Vegetation indices are algorithms aimed at simplifying data from multiple reflectance bands to a single value correlating with physical vegetation parameters, such as biomass, productivity, leaf area index, or percent vegetation ground cover [11]. Single band reflectance is combined into a vegetation index in order to minimize the effect of such factors as optical properties of the soil background and illumination and view geometric as well as 
meteorological factors on the canopy radiometric properties [12].

Vegetation indices, as summarized by Gross [13], are based on the characteristic reflection of plant leaves in the visible and near-infrared portions of light. By applying a "vegetation index" to the satellite imagery, concentration of green leaf vegetation can be quantified [14]. As explained by Liew [15] healthy vegetation has low reflection of visible light (from 0.4 to $0.7 \mu \mathrm{m}$ ), since the visible light is strongly absorbed by chlorophyll for photosynthesis and, at the same time, there is high reflection of near-infrared light (from 0.7 to $1.1 \mu \mathrm{m})$. The portion of reflected near-infrared light depends on the cell structure of the leaf [16]. In fading or unhealthy leaves, photosynthesis decreases and cell structure collapses resulting in an increase of reflected visible light and a decrease of reflected near-infrared light [13].

The normalized difference vegetation index (NDVI) has been considered to be a useful way for crop yield assessment models, using various approaches such as simple integration, to reflect vegetation greenness [17]. The index responds to changes in the amount of green biomass, chlorophyll content, and canopy water stress and, hence, is most commonly used in assessing crop vigor, vegetation cover, and biomass production from multispectral satellite data [18-20]. The NDVI is calculated from the near-infrared (NIR) and red (R) bands of either handheld or satellite sensors using the formula NDVI $=(\mathrm{NIR}-\mathrm{Red}) /(\mathrm{NIR}+\mathrm{Red})$.

The validity of crop yield models with NDVI is determined by the strength of association between the two variables included in the model [21]. It is also essential to have an understanding of the correlation existing between yield and NDVI at different phonological stages of crop for selecting appropriate date of satellite pass to include in the model [22].

Tobacco crop plays an important role in the economy of Zimbabwe, and in the 2012/2013 marketing season, 144 million $\mathrm{kg}$ of tobacco was sold, earning the country \$525 million [23]. Crop area and yield forecasts play an important role in stabilizing tobacco prices at the auction floors. Crop forecasting is the art of predicting crop yields and production before the harvest actually takes place, typically a couple of months in advance. Zimbabwe mostly relies on crop statistical forecasting/estimation, crop reports/field visits from extension officers, and statistical crop forecasts for crop yield forecasts [4]. However, data from crop estimates, which are obtained through surveys conducted after harvests, are in most countries available quite lately for early warning purposes.

An overestimation of the crop would jeopardize the grower's profit in that it causes fall in prices when supply exceeds the estimated volume. Underestimation, on the other hand, causes unnecessary panic and competition among buyers of the crop, causing a rise in the price of the crop. The timely evaluation of potential crop yields in general becomes important because of the huge economic impact crops have on the world markets [5] and in particular on the economy of Zimbabwe.

Remotely sensed measurements can be used in monitoring the effects of agronomic practices, which are considered in developing yield prediction models [24]. A more direct
TABLE 1: Variety-fertilizer treatments.

\begin{tabular}{ll}
\hline Treatment & Description \\
\hline$(1)$ & K RK 26-50\% recommended fertiliser \\
$(2)$ & K RK 26-recommended fertiliser \\
$(3)$ & K RK 26-150\% recommended fertiliser \\
$(4)$ & T 66-50\% recommended fertiliser \\
$(5)$ & T 66-recommended fertiliser \\
$(6)$ & T 66-150\% recommended fertiliser \\
$(7)$ & K E1-50\% recommended fertiliser \\
$(8)$ & K E1-recommended fertiliser \\
$(9)$ & K E1-150\% recommended fertiliser \\
\hline
\end{tabular}

remote sensing data yield, described in simple formulae, without deeper physiological background, is simpler to use and easier to understand [25] and would be applicable in tobacco, where the target, the leaf, is the harvestable part. This experiment investigated the relationship between canopy spectral characteristics of three tobacco varieties established on three planting dates and, under three fertilizer regimes, in-season dry matter and final yield. It was assumed in this study that the most suitable stage to predict yield is that where the canopy NDVI was most positively correlated with inseason dry mass, and a model relating the NDVI for this stage to cured leaf mass would be established. It was also hypothesized that the strength of the relationship between inseason dry mass and yields expressed as mass at untying with NDVI is not affected by tobacco variety, planting date, and fertiliser application rate. The results for the project will be used to select the most appropriate stage of collecting remote sensing data for field level and national tobacco crop area and yield forecasting. This information could be very useful in relating the reflectance measured from the tobacco cropped lands to in-season crop condition and final yield and quality predictions using remote sensing.

\section{Method}

Study Area. The experiment was conducted at Kutsaga Research Station in Zimbabwe in the 2010-2012 cropping seasons. Kutsaga is located between longitude $31^{\circ} 08^{\prime} \mathrm{E}$, latitude $17^{\circ} 55^{\prime} \mathrm{S}$, and at an altitude of $1000 \mathrm{~m}$ to $1500 \mathrm{~m}$ [10]. The longterm annual average rainfall is $850 \mathrm{~mm}$.

The experimental plots were located on well-drained granitic sands. During February of 2009 and 2010 the plots were disked after a three-year Katambora grass fallow period to incorporate grass. Agricultural lime was applied using recommendations given from soil test results to raise the soil $\mathrm{pH}$ from 5.3 to 6.3 optimum for tobacco production. For the three years preceding the 2008 experiments, the sites were under Katambora grass to control nematodes. Recommended cultural and management practices were followed [10], except regard N:P:K levels and planting times, which were treatments in the experiment.

2.1. Fertilizer Treatments. In order to establish the relationship between spectral data and yield, there was a need to create variable growth conditions [26], and three varieties, 


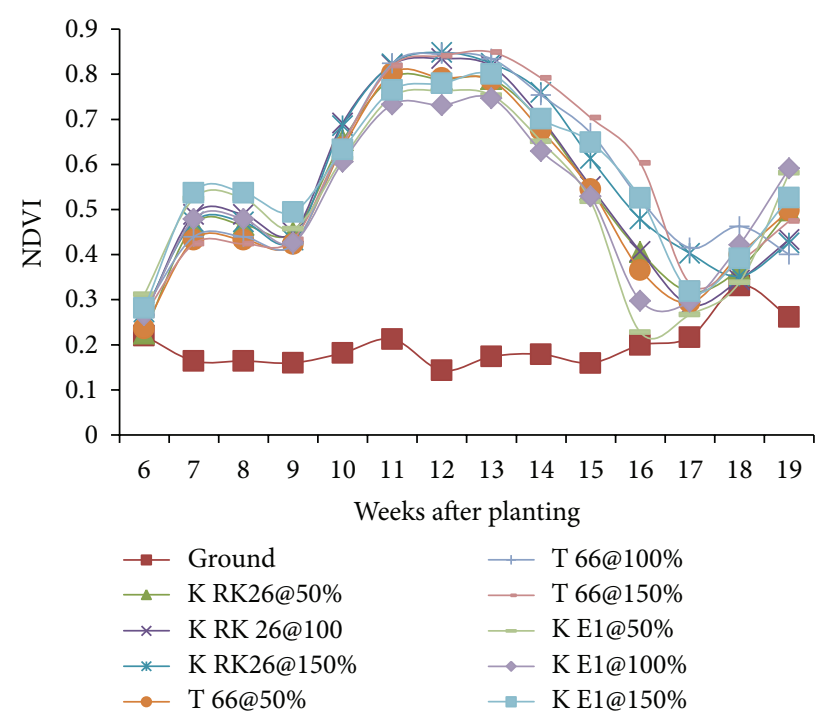

(a)

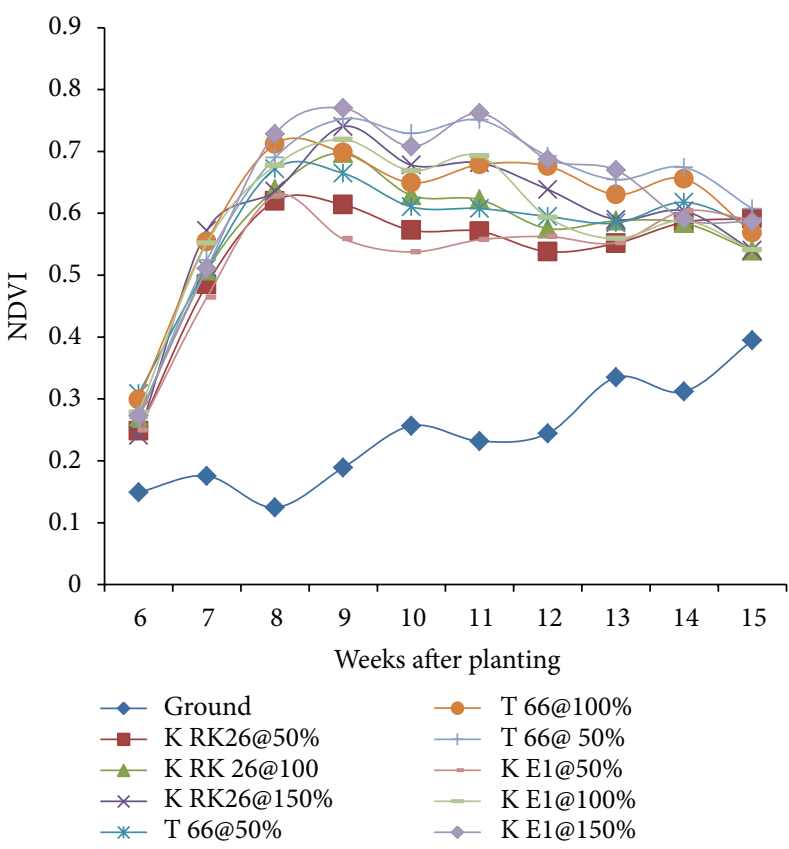

(c)

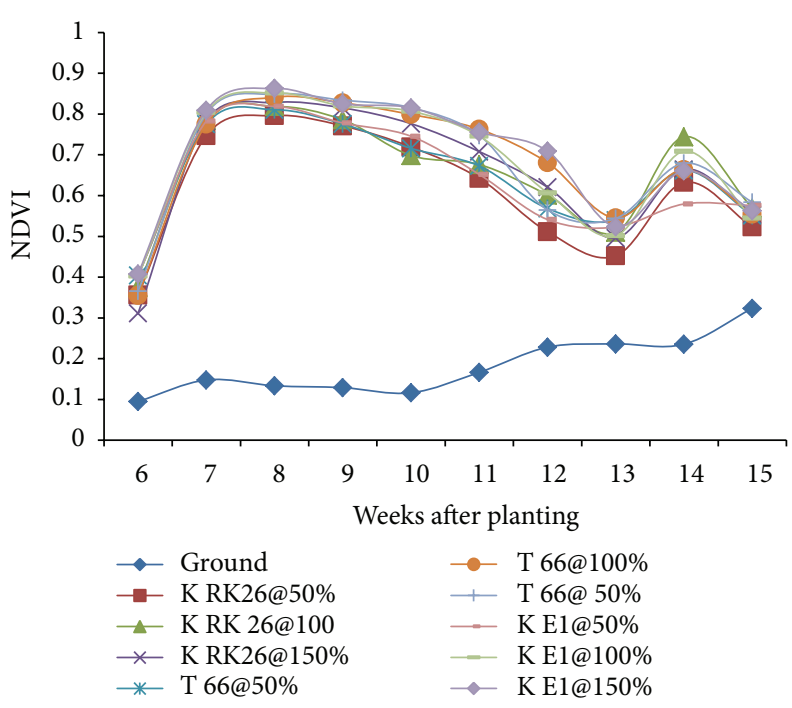

(b)

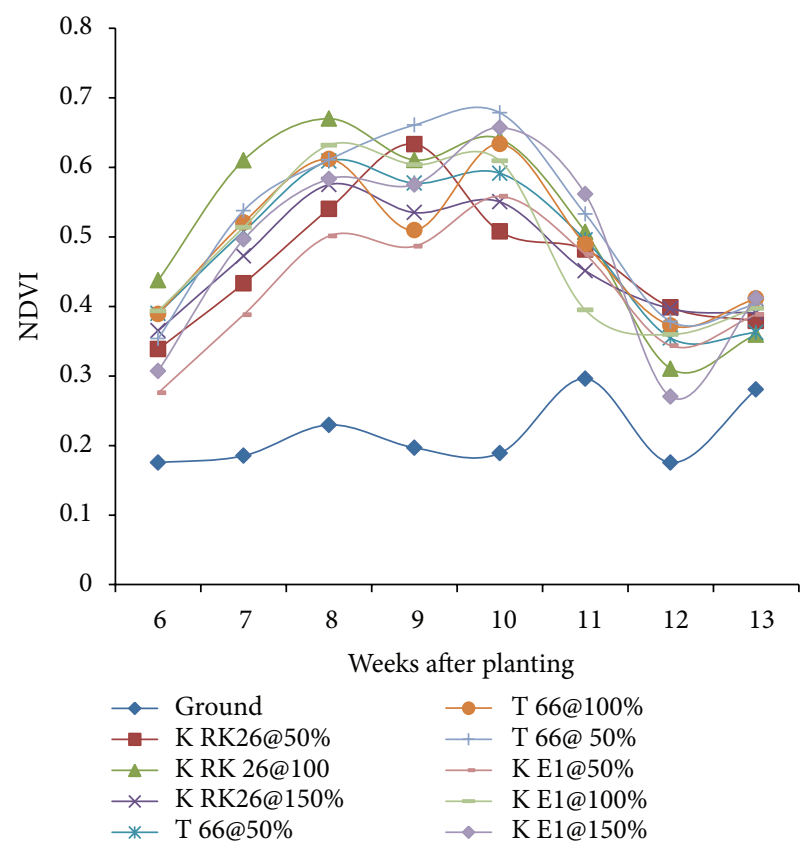

(d)

Figure 1: The NDVI temporal profiles for the (a) September, (b) October, (c) November, and (d) December planted crops.

four planting dates, and three fertiliser levels were tested. The variety-fertilizer treatments were applied by hands as shown in Table 1. The N:P:K treatment was hand-applied in bands about $10 \mathrm{~cm}$ deep and $30 \mathrm{~cm}$ to each side of a row at planting, while $\mathrm{N}$ treatments were applied at about 4 weeks after transplanting and after topping (at 6 weeks after planting).

The experiment was laid out in a completely randomized design with plantings on September 15, October 15, November 15, and December 15 each with 9 variety $\times$ fertiliser management treatments (Table 1 ). Three tobacco varieties $\mathrm{K}$ RK26, T 66, and K E1, developed by Kutsaga Research Station, were used, while three fertiliser management levels
(50\%, 100\%, and $150 \%$ recommended) were applied by hand (Table 1). The recommended compound fertiliser rate from soil test results was $700 \mathrm{~kg} / \mathrm{ha}$, while that for ammonium nitrate $(34.5 \% \mathrm{~N})$ was $96 \mathrm{~kg} / \mathrm{ha}$ at 4 weeks after planting and $75 \mathrm{~kg} / \mathrm{ha}$ after topping.

2.2. Procedure. Radiometric measurements were made weekly from the age of 6 weeks after planting on $5 \mathrm{~m} \times$ $5 \mathrm{~m}$ square sampling plots, using a handheld multispectral radiometer (Cropscan MSR-5, 450-1750 nm), with the FOV centering over rows. All treatment applications had been completed at this stage of development. 


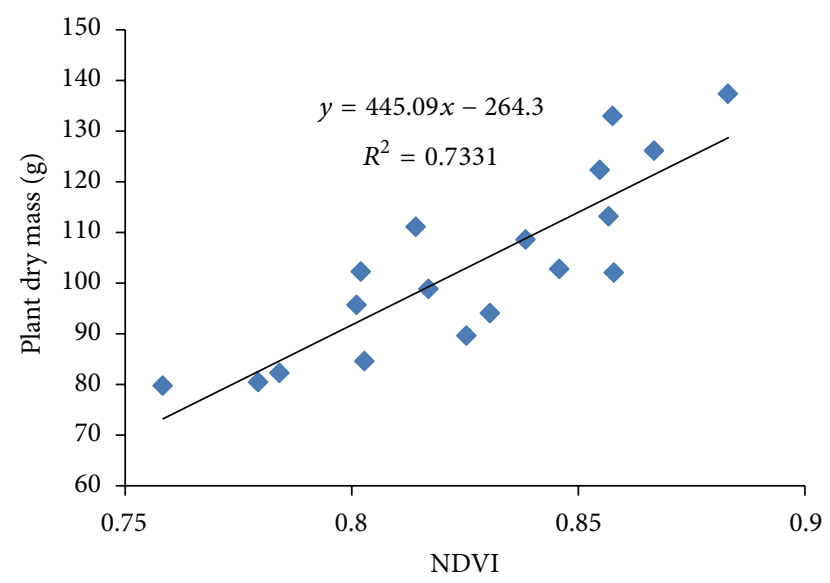

(a)

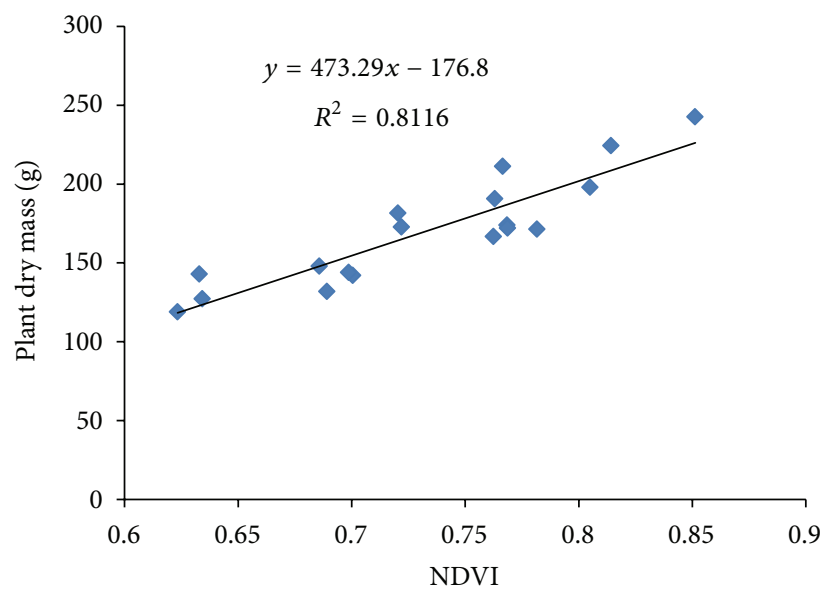

(c)

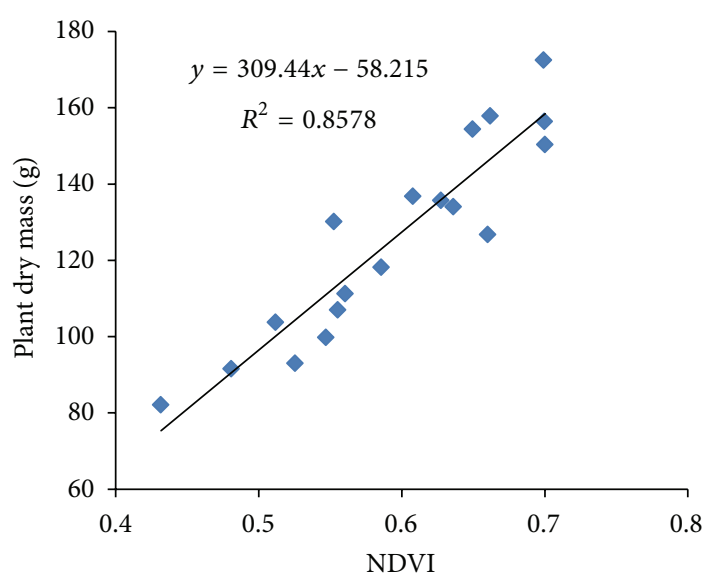

(b)

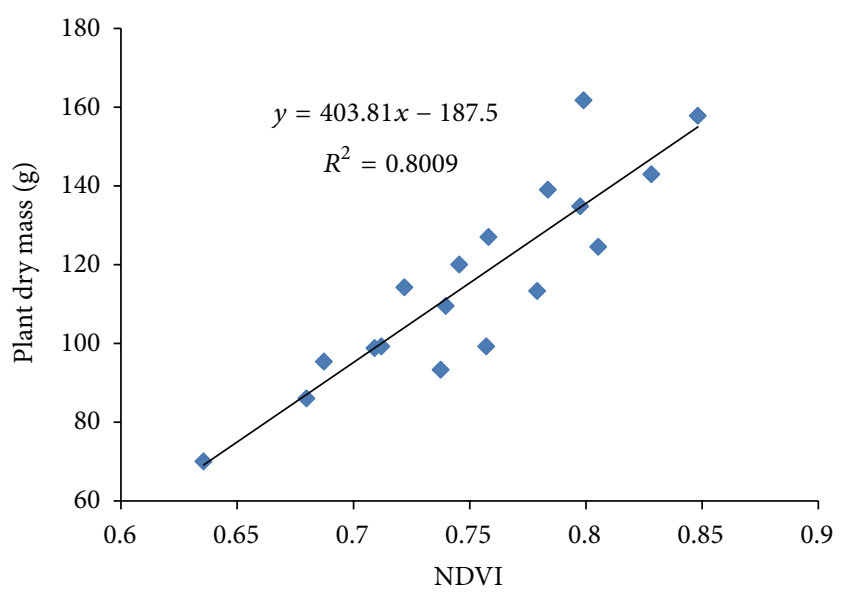

(d)

Figure 2: Dry-mass-reflectance correlations for the flue-cured tobacco samples collected from the (a) September, (b) October, (c) November, and (d) December planted crops.

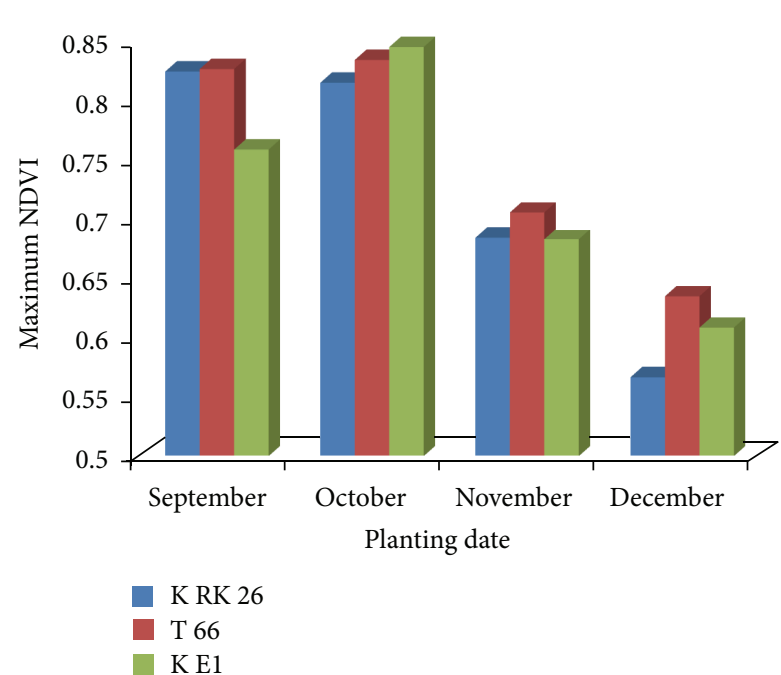

(a)

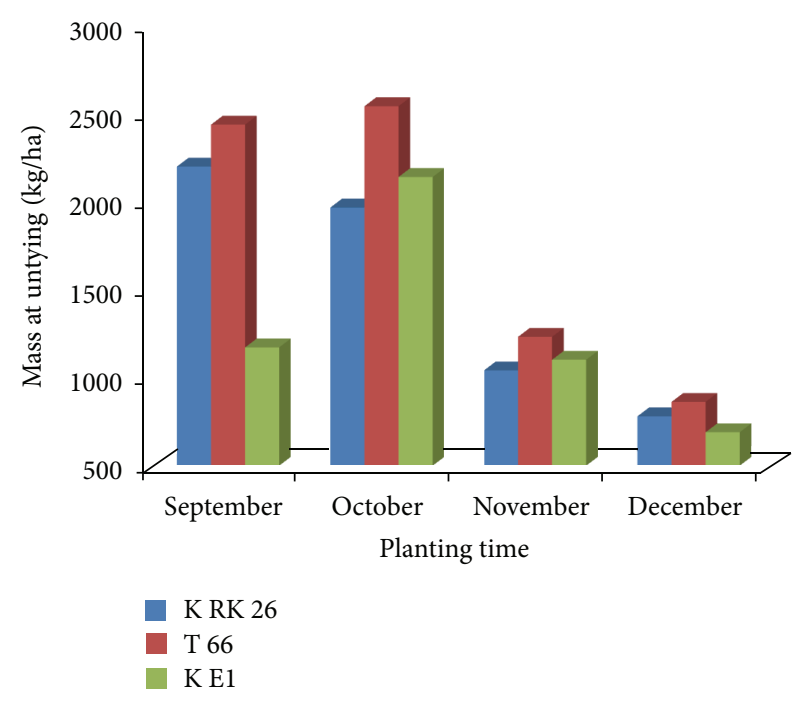

(b)

FIgURE 3: (a) Tobacco varieties' maximum NDVI and (b) mass at untying response to planting date. 


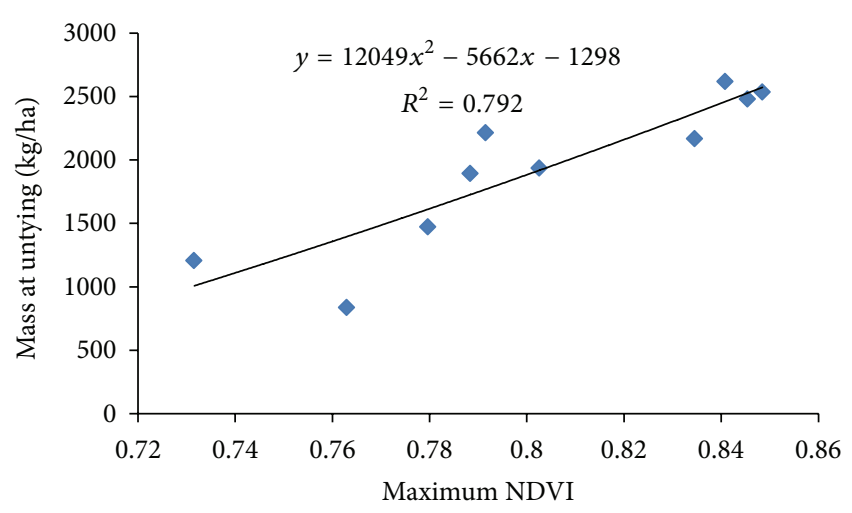

(a)

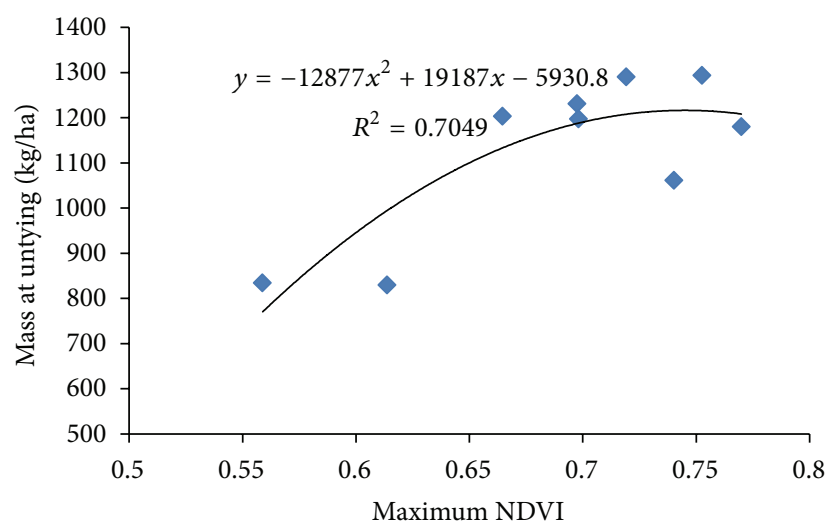

(c)

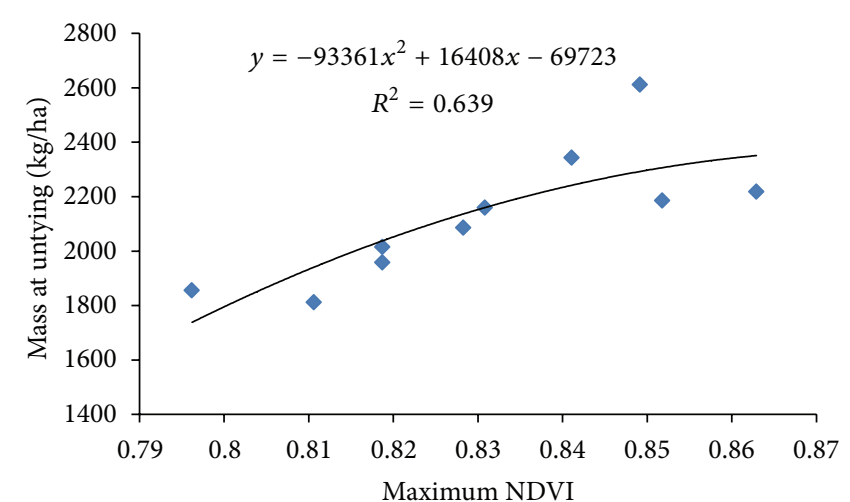

(b)

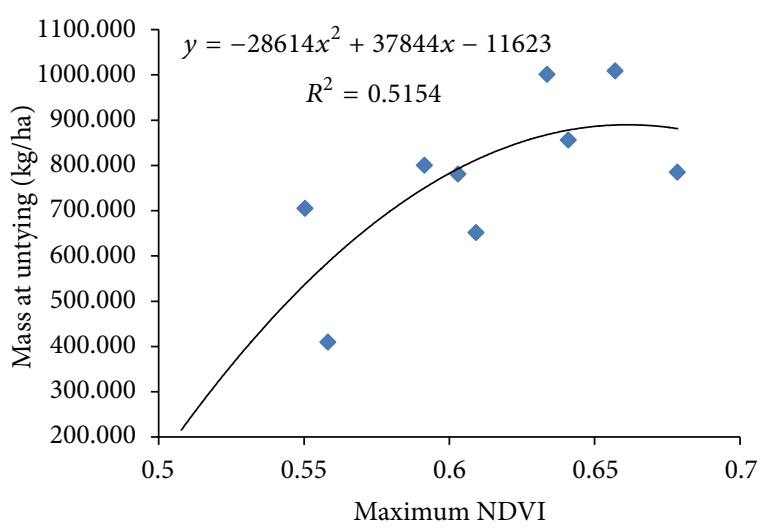

(d)

Figure 4: The relationship between the (a) September, (b) October, (c) November, and (d) December planted tobacco mass at untying and maximum NDVI.

Spectral data from the 4 planting dates were used to construct temporal NDVI profiles and one, with uninterrupted growth was selected for the in-season dry-mass-NDVI regression analysis. Above ground samples were collected after a corresponding canopy reflectance measurement had been obtained. Some 10 plants were sampled from each variety $\times$ fertiliser $\times$ planting time treatment after spectral data collection at $8,10,12$, and 14 weeks after planting. The data collection timing, during midday and under cloudless conditions across the growing season, could include bare soil, early crop growth stage, peak crop greenness, and crop maturity imagery [27].

Each sampling plot measured consisted 5 rows of each with 32 plants spaced at $56 \mathrm{~cm}$. The interrow distance was $1.2 \mathrm{~m}$. normalized difference vegetation indices (NDVI) was calculated from the spectral bands obtained in Channels 3 and 4 of the MSR 5 which correspond to the visible (VIS) and near-infra red (NIR), respectively, using the following formula:

$$
\mathrm{NDVI}=\frac{\text { nir }- \text { red }}{\text { nir }+ \text { red }}
$$

The multispectral radiometer (MRS 5) was positioned facing vertically downward at $1 \mathrm{~m}$ above crop canopies, and measurements were taken around solar noon to minimize the effect of diurnal changes in solar zenith angle. In total, 10 measurements were taken per sampling area and reflectance measurements were then averaged for each sampling plot to estimate a single reflectance value. Mature leaves were harvested from one row, cured, and yield determined before handle losses during crop grading as applied by Zhang et al. [28].

Reflectance measurements were also taken on individual plants from the other 3 rows. After taking reflectance readings, the above ground whole plants were harvested and packed in khaki bags and dried in microbarns. Dry matter measurements were later taken for reflectance/DM regression analysis. Three rows were also harvested and cured and mass was determined just after curing, before handling losses were incurred. The NDVI for the growth stage where there is the highest in-season dry-mass-NDVI correlation was selected for determining the mass-at-untying NDVI correlations.

Three-dimensional positions, latitude, longitude, and altitude, for the whole experimental area and for each treatment plot will be taken using a Garmin personal navigator (GPS V) to enable repeated sampling at the same location. Yield data were collected at harvest.

2.3. Data Analysis. NDVI data was analysed by analysis of variance and statistically significant treatment effects were 


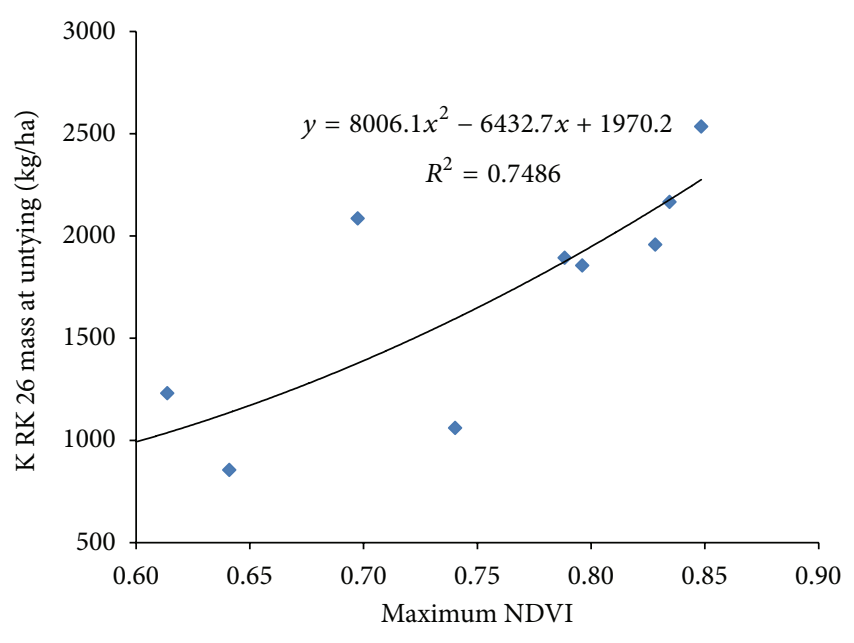

(a)

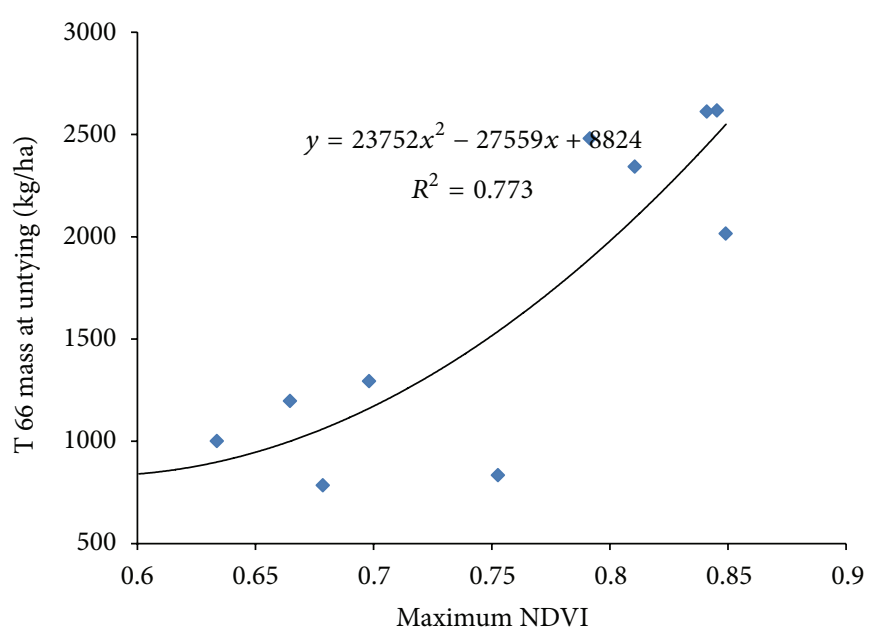

(b)

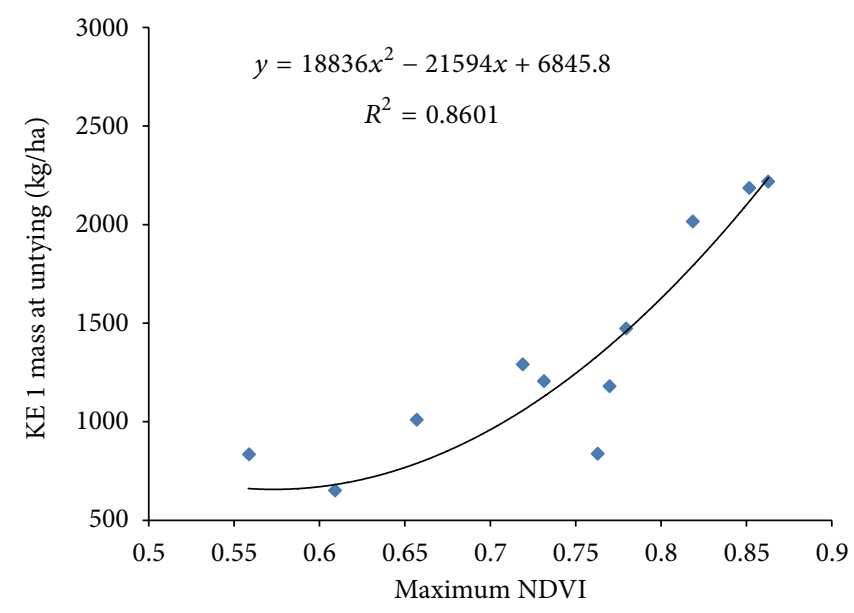

(c)

FIGURE 5: The relationship between tobacco varieties (a) K RK26, (b) T 66, and (c) K E1 mass at untying and maximum NDVI.

separated using least significant differences (LSDs). The data was analysed using the Genstat 9.2 statistical package at 5\% level of significance. Student's $t$-test calculations were done to compare the planting date effect, and graphs were plotted using Excel 2007.

\section{Results}

The NDVI for all four planting date treatments crop rose from week 6 after planting to peak from 9 to 12 weeks after planting (Figure 1). At eight weeks after planting all the variety $\times$ fertiliser treatments in all, except for the December crop, started showing significant $(P<0.05)$ treatment differences. Beyond the peak, the NDVI also fell gently to reach the minimum at 13 weeks of age. The October crop (Figure 1(b)) was sampled for NDVI versus in-season dry mass analysis. This crop was selected because it was not subjected to long dry conditions after planting and had a good establishment. In addition temporal NDVI profile for the planting date had the highest NDVI value, which would enable a wide variation of the DM-NDVI relationships (Figure 1(b)).
The correlation between NDVI and in-season dry mass became stronger from the first sampling date ( 8 weeks after planting), reaching the highest at 10 weeks and later declined (Figure 2). Plants were not sampled after week 14 because reaping had become intense and some plants had already been stripped.

The NDVI response to variety $\times$ fertiliser treatment was similar to that for mass at untying (Figure 3 ). There was a general decline in both maximum NDVI and mass at untying with later planting, with the least values attained in December planting.

The mass at untying-NDVI coeficient of determination also decreased with later planting, with least being that of December (Figure 4). In all the four planting date treatments, the best fitting curves for mass at untying and NDVI correlations were quadratic. The September coefficient of determination $\left(r^{2}=0.79\right)$ was the highest as compared to October $\left(r^{2}=0.594\right)$, November $\left(r^{2}=0.695\right)$, and December $\left(r^{2}=0.515\right)$.

The September and the October crop reflectance values were statistically similar $(P>0.05)$, while the November and 


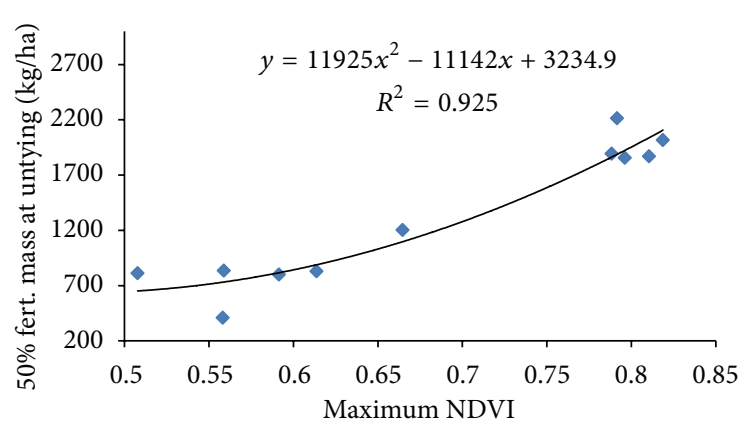

(a)

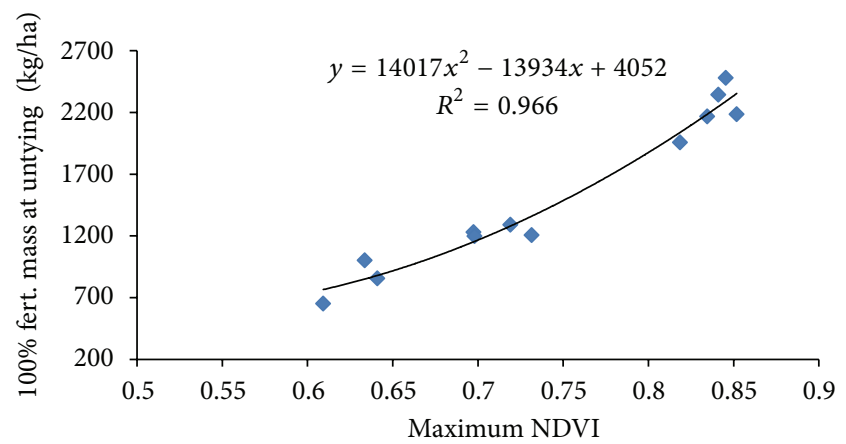

(b)

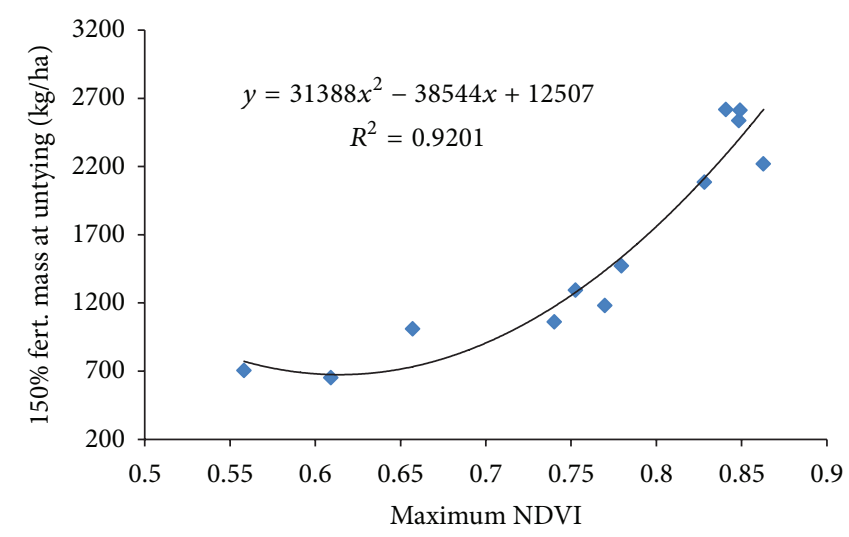

(c)

FiguRE 6: The relationship between tobacco mass at untying for the (a) 50\%, (b) 100\%, and (c) $150 \%$ fertiliser rate treatments and maximum NDVI.

TABLE 2: $t$-test for the comparison of mean maximum NDVI values for the different planting date treatments.

\begin{tabular}{lccc}
\hline & \multicolumn{3}{c}{$P$ values } \\
& October & November & December \\
\hline September & 0.058204 & 0.000494993 & $4.883 E-06$ \\
October & & $5.66702 E-06$ & $1.08556 E-08$ \\
November & & & 0.000152201 \\
\hline
\end{tabular}

the December reflectance values were, for each, significantly different $(P<0.05)$ from all the rest (Table 2).

All the three varieties, K RK 26, T 66, and K E1, showed a quadratic relatioship between mass at untying and NDVI (Figure 5). K E1 had the highest $\left(r^{2}=0.86\right)$ mass at untying NDVI coefficient of determination. The mass at untying NDVI correlations in K E1 $\left(r^{2}=0.748\right)$ and T $66\left(r^{2}=0.773\right)$ were comparable. In all the three varieties, the best fitting curves for mass at untying versus NDVI correlations were also quadratic, with comparable gradients at NDVI values between 0.65 and 0.75 (Table 3 ).

All the three fertiliser levels, $50 \%\left(r^{2}=0.925\right), 100 \%$ $\left(r^{2}=0.966\right), 150 \%\left(r^{2}=0.92\right)$, displayed equally strong mass at untying NDVI relationship (Figure 6) with comparable gradients, again at NDVI value between 0.65 and 0.7 (Table 4).
TABLE 3: Variety yield-NDVI gradients at NDVI $=0.65,0.7$, and 0.75 .

\begin{tabular}{lccc}
\hline NDVI & 0.65 & 0.7 & 0.75 \\
& & Yield-NDVI gradient \\
\hline K RK 26 & 4456.16 & 4776.4 & 5256.76 \\
T66 & 4505.72 & 5448.8 & 6863.42 \\
KE 1 & 4022.96 & 4776.4 & 5906.56 \\
\hline
\end{tabular}

TABLE 4: Fertiliser level yield-NDVI gradients at NDVI $=0.65,0.7$, and 0.75 .

\begin{tabular}{lccc}
\hline NDVI & 0.65 & 0.7 & 0.75 \\
& \multicolumn{3}{c}{ Yield-NDVI gradient } \\
\hline 50\% fertiliser level & 4360.5 & 5553.0 & 6745.5 \\
$100 \%$ fertiliser level & 4288.1 & 5689.8 & 7091.5 \\
$150 \%$ fertiliser level & 2260.4 & 5399.2 & 8538.0 \\
\hline
\end{tabular}

The yield, expressed as mass at untying ( $\mathrm{kg} / \mathrm{ha})$, for the September-October, November, and December planting can, therefore be estimated separately by the models in Figure 7:

(1) $y=-26708 x^{2}+54365 x-24516$,

$$
R^{2}=0.741,
$$




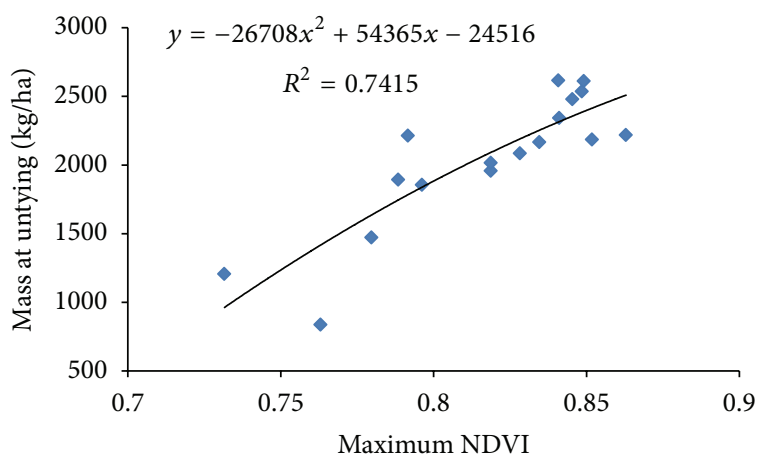

(a)

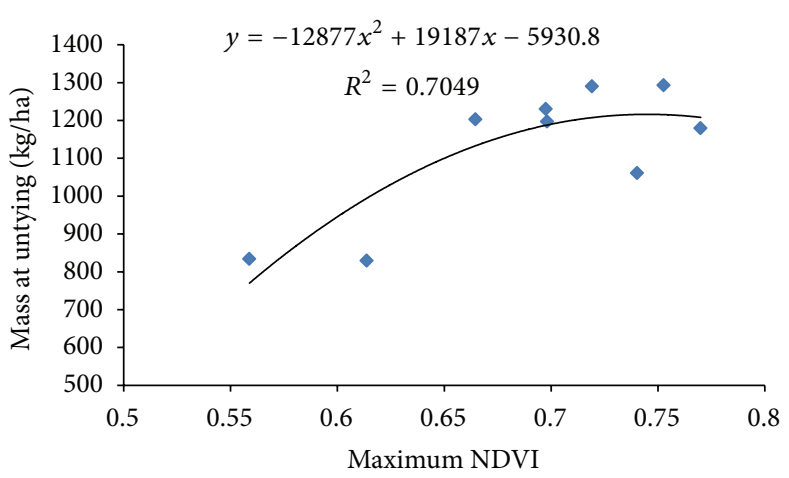

(b)

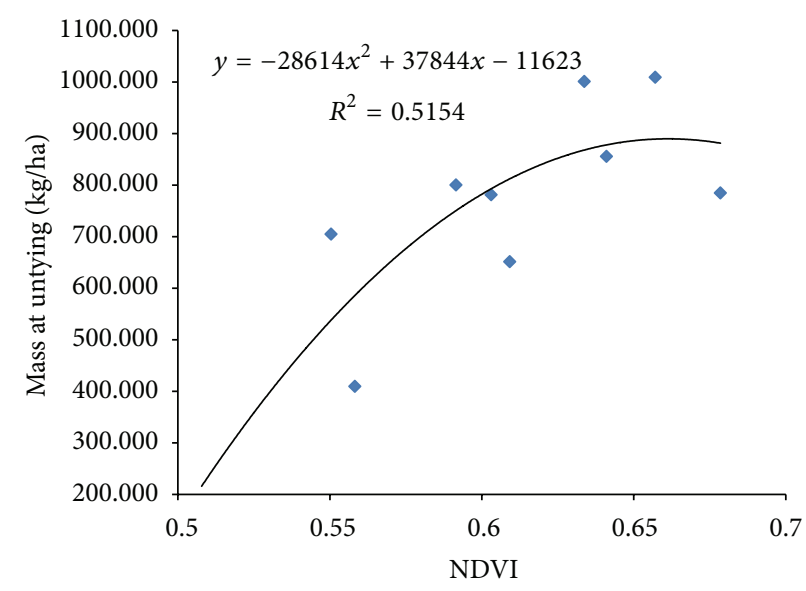

(c)

Figure 7: The relationship between tobacco mass at untying for the (a) September-October, (b) November, and (c) December planted crops and maximum NDVI.

(2) $y=-12877 x^{2}+19187 x-5930$,

$$
R^{2}=0.704
$$

(3) $y=-28614 x^{2}+37844 x-11623$,

$$
R^{2}=0.515
$$

where $y$ is the mass at untying and $x$ is the maximum normalised difference vegetative index (NDVI).

\section{Discussions}

The October crop was selected for in-season dry mass-NDVI analysis because of the clear cloudless conditions during the times of data collection. Thin cloud coverage, according to Nuarsa et al. [29], can lead to inconsistencies in the reflectance values, which will affect the NDVI, and, therefore, the selection of cloud-free images is one of the most important steps in the data analysis.

The NDVI-yield relationship increases with age up to 10-12-week after planting. As Nageswara-Rao et al. [30] explained it, the changes in spectral response of a crop are a function of phenological stages of the crop. The 10-12 weeks period, with the highest correlation, could be an indication of the most suitable phenological stage to collect satellite data for yield forecasting.

Chlorophyll degradation related leaf ripening occurring during the ripening stage causes an increase in the red spectral reflectance which is normally absorbed by chlorophyll [31]. On the contrary, the NIR spectral reflectance is decreased due to a change in leaf internal structure [31] resulting in the fall of NDVI [32]. The fall in the in-season dry-mass-NDVI relationship after 14 weeks of age is related to the decrease in canopy reflectance spectra decrease at crop maturity stage that is brought about by reaping [33], while the final yield, in the data analysis, remains unchanged.

The decrease in tobacco mass at untying with later planting at all variety $\times$ fertiliser treatments was long since established [10]. Apparently the maximum NDVI in this experiment also followed the same trend, indicating a positive relationship between the two.

The similarity in the coefficients of determination between mass at untying and NDVI for the September and October planted crops could be an indication of the need to combine the three, when assessing area and yield using remote sensing, while the November and the December crops could each be assessed separately. The high coefficients of determination for all the three varieties and fertilizer levels could also be an indication of the possibility to disregard the 
variety and fertiliser differences in the processes of developing yield forecasting models.

The coefficients of determination between mass at untying and NDVI for the September-October (0.741) and the November (0.704) planted crops were higher than the 0.65 reported by Povkh et al. [34] but lower than the $r^{2}=$ $0.90-0.98$ that Jiang et al. [35] found between wheat grain yield and NDVI. The established coefficients in this experiment were, however, high enough for tobacco yield to be estimated using Cropscan calculated NDVI. The yield models derived were quadratic, similar to the findings of Jiang et al. [35] in wheat. The high value of $R^{2}$ indicated that the relationship between tobacco yield and the NDVI was consistent [29]. The December crop coefficient of determination was, however, low (0.515) meaning that yield estimation for this crop would not be accurately made using the model.

As the channels of the sensor used in the experiment is LANDSAT Thematic Mapper compatible [36], the models derived can be applicable in tobacco yield estimation using operation remote sensing data from the satellite.

However, more work is needed to establish the relationship between the Cropscan reflectance and those for selected Satellite platforms like Modis, Landsat 5 and Landsat TM which have been used for the same purpose in other crops [37].

\section{Conclusions}

The NDVI is positively related to in-season dry mass and, can be used to assess crop health, tobacco response to fertilizer, and accurate monitoring of crop development patterns for yield forecasting purposes. For yield forecasting purposes, the September and the October crops could be estimated together, while the November and the December crops each could also be estimated, separately. There was a strong positive correlation between NDVI and flue-cured tobacco yield at all fertiliser levels and for all the tested varieties, and, hence, for yield forecasting purposes, one may not separate these factors. There is, however, a need to establish the relationship between Cropscan multispectral radiometer 5 data and various satellite platforms before this information can be applied in satellite remote sensing.

\section{Acknowledgments}

The authors are grateful to the Tobacco Research Board/ Kutsaga Research Station for funding this series of experiments on developing-flue cured tobacco crop area and yield forecasting models using remote sensing and agronomic techniques.

\section{References}

[1] C. A. Reynolds, M. Yitayew, D. C. Slack, C. F. Hutchinson, A. Huetes, and M. S. Petersen, "Estimating crop yields and production by integrating the FAO Crop Specific Water Balance model with real-time satellite data and ground-based ancillary data," International Journal of Remote Sensing, vol. 21, no. 18, pp. 34873508, 2000.
[2] S. Landau, R. A. C. Mitchell, V. Barnett, J. J. Colls, J. Craigon, and R. W. Payne, "A parsimonious, multiple-regression model of wheat yield response to environment," Agricultural and Forest Meteorology, vol. 101, no. 2-3, pp. 151-166, 2000.

[3] T. R. Wheeler, P. Q. Craufurd, R. H. Ellis, J. R. Porter, and P. V. Vara Prasad, "Temperature variability and the yield of annual crops," Agriculture, Ecosystems and Environment, vol. 82, no. 13, pp. 159-167, 2000.

[4] SADC, Selected Technical Papers: Methodology of Food Crop Forecasting in SAD, SADC Secretariat, Gaborone, Botswana, 2009.

[5] P. C. Doraiswamy, B. Akhmedovb, L. Beardc, A. Sterna, and R. Mueller, "Operational prediction of crop yields using MODIS data and products," in Proceedings of the International Achives of Photogrametry, Remote Sensing and Spatial Information Sciences, vol. 38, pp. 45-50, 2011.

[6] F. Tao, M. Yokozawa, Z. Zhang, Y. Xu, and Y. Hayashi, "Remote sensing of crop production in China by production efficiency models: models comparisons, estimates and uncertainties," Ecological Modelling, vol. 183, no. 4, pp. 385-396, 2005.

[7] P. C. Doraiswamy, J. L. Hatfield, T. J. Jackson, B. Akhmedov, J. Prueger, and A. Stern, "Crop condition and yield simulations using Landsat and MODIS," Remote Sensing of Environment, vol. 92, no. 4, pp. 548-559, 2004.

[8] F. Rembold, C. Atzberger, I. Savin, and O. Rojas, "Using low resolution satellite imagery for Yield prediction. and yield anomaly detection," Remote Sensing, vol. 5, no. 4, pp. 1704-1733, 2013.

[9] A. D. Baez-Gonzalez, J. R. Kiniry, S. J. Maas et al., "Large-area maize yield forecasting using leaf area index based yield model," Agronomy Journal, vol. 97, no. 2, pp. 418-425, 2005.

[10] Tobacco Research Board (TRB), Flue Cured Tobacco Recommendations, TRB, Harare, Zimbabwe, 2012.

[11] C. J. Tucker, "Red and photographic infrared linear combinations for monitoring vegetation," Remote Sensing of Environment, vol. 8, no. 2, pp. 127-150, 1979.

[12] J. Verrelst, B. Koetz, M. Kneubühler, and M. Schaepman, "Directional sensitivity analysis of vegetation indices from multiangular CHRIS/PROBA data," in Proceedings of the ISPRS Commission VII Mid-Term Symposium, N. Kerle and A. Skidmore, Eds., Enschede, The Netherlands.

[13] D. Gross, Monitoring Agricultural Biomass Using NDVI Time Series, Food and Agriculture Organization of the United Nations (FAO), Rome, Italy, 2005.

[14] A. Viña, A. A. Gitelson, A. L. Nguy-Robertson, and Y. Peng, "Comparison of different vegetation indices for the remote assessment of green leaf area index of crops," Remote Sensing of Environment, vol. 115, no. 12, pp. 3468-3478, 2011.

[15] S. C. Liew, "Principles of Remote Sensing," Centre for Remote Imaging, Sensing and Processing, National University of Singapore, Singapore, 2001, http://www.crisp.nus.edu.sg/ research/ tutorial/rsmain.htm.

[16] J. T. Woolley, "Reflectance and Transmittance of Light by Leaves," Plant Physiology, vol. 47, pp. 656-662, 1970.

[17] A. K. Prasad, L. Chai, R. P. Singh, and M. Kafatos, "Crop yield estimation model for Iowa using remote sensing and surface parameters," International Journal of Applied Earth Observation and Geoinformation, vol. 8, no. 1, pp. 26-33, 2006.

[18] J. U. H. Eitel, R. F. Keefe, D. S. Long, A. S. Davis, and L. A. Vierling, "Active ground optical remote sensing for improved monitoring of seedling stress in nurseries," Sensors, vol. 10, no. 4, pp. 2843-2850, 2010. 
[19] X. Yin, A. McClure, and D. Tyler, "Relationships of plant height and canopy NDVI with nitrogen nutrition and yields of corn," in Proceedings of the 19th World Congress of Soil Science, Soil Solutions for a Changing World, Brisbane, Australia, August 2010.

[20] R. D. Jackson, P. N. Slater, and P. J. Pinter Jr., "Discrimination of growth and water stress in wheat by various vegetation indices through clear and turbid atmospheres," Remote Sensing of Environment, vol. 13, no. 3, pp. 187-208, 1983.

[21] C. S. Muthy, S. Jonna, P. V. Raju, S. Thurivengadachari, and K. A. Hakeem, "Crop Yield Prediction in Command Area using Satellite Data," GISdevelopment.net, AARS, ACRS 1994, Poster Session.

[22] T. Engel, G. Hoogenboom, J. W. Jones, and P. W. Wilkens, "AEGIS/WIN: a computer program for the application of crop simulation models across geographic areas," Agronomy Journal, vol. 89, no. 6, pp. 919-928, 1997.

[23] Tobacco Industries Marketing Board (T.I.M.B), Annual Report and Accounts For the Year Ended 30 June, 2011, T.I.M.B, Harare, Zimbabwe, 2012.

[24] C. Atzberger, "Advances in remote sensing of agriculture: context description, existing operational monitoring systems and major information needs," Remote Sensing, vol. 5, pp. 949-981, 2012.

[25] C. Ferencz, P. Bognár, J. Lichtenberger et al., "Crop yield estimation by satellite remote sensing," International Journal of Remote Sensing, vol. 25, no. 20, pp. 4113-4149, 2004.

[26] S. A. Mohammad, "Spectral indices and agronomic variables relationship of cotton (Gossypium sps.) under sowing dates and nitrogen levels," Asian Conference for Remote Sensing, 2008, http://www.gisdevelopment.net/application/agriculture/yield/ mi08_305.htm.

[27] K. Dalsted and L. Queen, "Interpreting remote sensing data," The Site-Specific Management Guideline SSMG-26.

[28] H. Zhang, H. Chen, and G. Zhou, "The model of wheat yield forecast based on modis-ndvi: a case study of xinxiang," in Proceedings of the ISPRS Annals of the Photogrammetry, Remote Sensing and Spatial Information Sciences Congress, Melbourne, Australia, August 2012.

[29] I. W. Nuarsa, F. Nishio, and H. Chiharu, "Rice yield estimation using landsat ETM+ data and field observation," Journal of Agricultural Science, vol. 4, no. 3, pp. 45-56, 2012.

[30] R. C. Nageswara-Rao, J. H. Williams, M. V. K. Sivakumar, and K. D. R. Wadia, "Effect of water deficit at different growth phases of groundnut. II. Response to drought during pre-flowering phas," Agronomy Journal, vol. 80, pp. 431-438, 1988.

[31] W. Gunnula, M. Kosittrakun, T. L. Righetti, P. Weerathaworn, and M. Prabpan, "Normalized difference vegetation index relationships with rainfall patterns and yield in small plantings of rain-fed sugarcane," Australian Journal of Crop Science, vol. 5, no. 13, pp. 1852-1857, 2011.

[32] D. M. Gates, H. J. Keegan, J. C. Schleter, and V. R. Weidner, "Spectral properties of plants," Applied Optics, vol. 4, no. 1, pp. 11-20, 1965.

[33] H. Qiao, W. Mei, Y. Yang, W. Yong, J. Zhang, and Y. Hua, "Study on relationship between tobacco canopy spectra and LAI," IFIP Advances in Information and Communication Technology, vol. 345, no. 2, pp. 650-657, 2011.

[34] V. Povkh, G. L. Shljakhova, Garbuzov, and E. Vorobeychik, "Operational monitoring of the agricultural production based on the observational MODIS data as a support for improving regional planning," in Proceedings Of The International Symposium On Remote Sensing Of Environment, South Regional Information and Analytical Center (SRIA-Center), Rostov-onDon, RUSSIA, 2005.

[35] D. Jiang, N.-B. Wang, X.-H. Yang, and J.-H. Wang, "Study on the interaction between NDVI profile and the growing status of crops," Chinese Geographical Science, vol. 13, no. 1, pp. 62-65, 2003.

[36] I. C. T. International, Multispectral Radiometers, ICT International, 2003.

[37] C. Yang, J. H. Everitt, and J. M. Bradford, "Using high resolution QuickBird satellite imagery for cotton yield estimation," in Proceedings of the ASAE Annual International Meeting, pp. 893904, August 2004. 


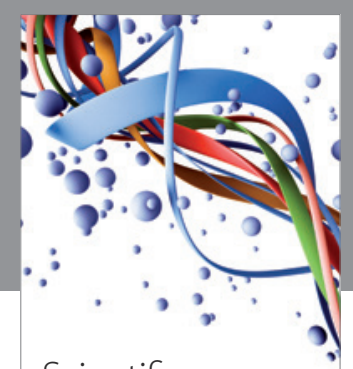

Scientifica
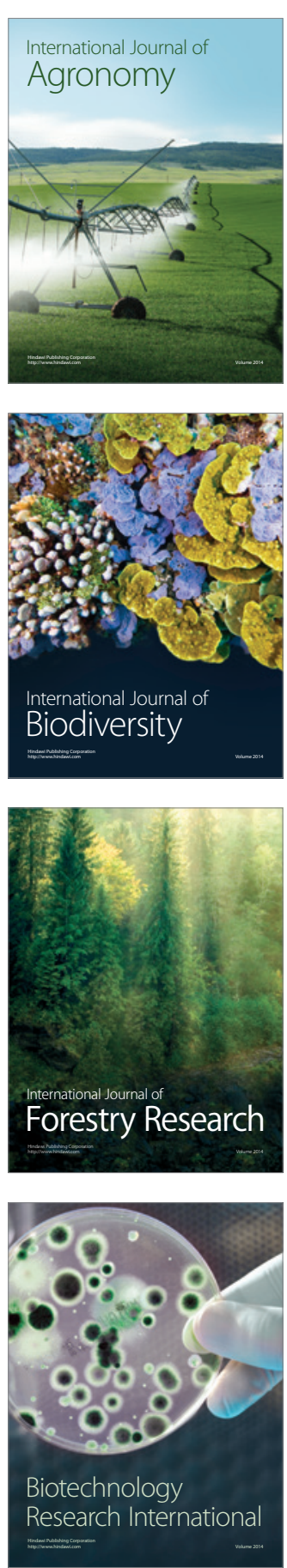
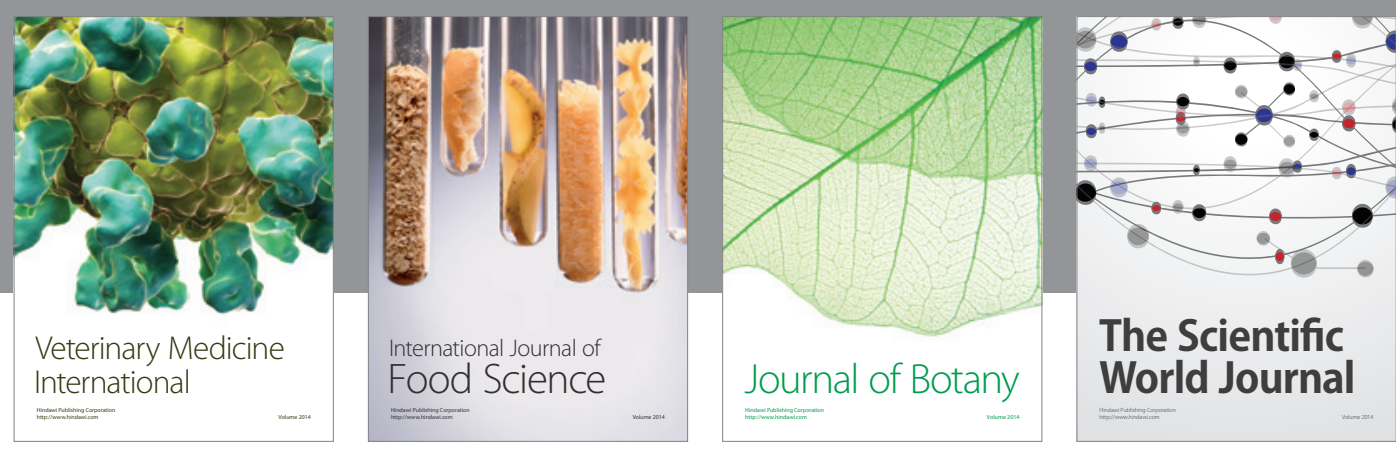

The Scientific World Journal
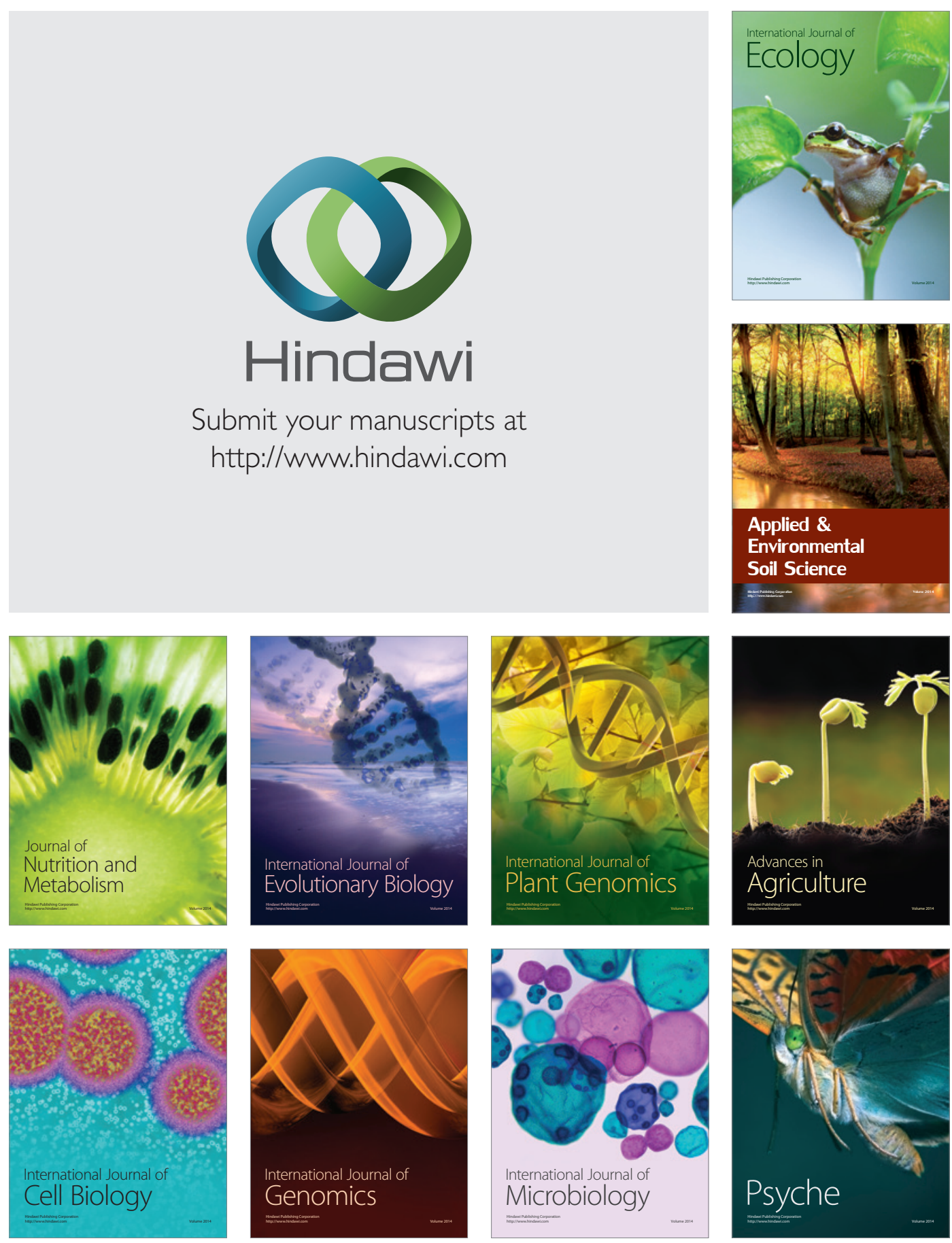